\title{
Fermentative Degradation of Polyethylene Glycol by a Strictly Anaerobic, Gram-Negative, Nonsporeforming Bacterium, Pelobacter venetianus sp. nov.
}

\author{
BERNHARD SCHINK* AND MARION STIEB \\ Fakultät für Biologie, Universität Konstanz, D-7750 Konstanz, West Germany
}

Received 7 December 1982/Accepted 17 March 1983

\begin{abstract}
The synthetic polyether polyethylene glycol (PEG) with a molecular weight of 20,000 was anaerobically degraded in enrichment cultures inoculated with mud of limnic and marine origins. Three strains (Gra PEG 1, Gra PEG 2, and Ko PEG 2) of rod-shaped, gram-negative, nonsporeforming, strictly anaerobic bacteria were isolated in mineral medium with PEG as the sole source of carbon and energy. All strains degraded dimers, oligomers, and polymers of PEG up to a molecular weight of 20,000 completely by fermentation to nearly equal amounts of acetate and ethanol. The monomer ethylene glycol was not degraded. An ethylene glycolfermenting anaerobe (strain Gra EG 12) isolated from the same enrichments was identified as Acetobacterium woodii. The PEG-fermenting strains did not excrete extracellular depolymerizing enzymes and were inhibited by ethylene glycol, probably owing to a blocking of the cellular uptake system. PEG, some PEGcontaining nonionic detergents, 1,2-propanediol, 1,2-butanediol, glycerol, and acetoin were the only growth substrates utilized of a broad variety of sugars, organic acids, and alcohols. The isolates did not reduce sulfate, sulfur, thiosulfate, or nitrate and were independent of growth factors. In coculture with $A$. woodii or Methanospirillum hungatei, PEGs and ethanol were completely fermented to acetate (and methane). A marine isolate is described as the type strain of a new species, Pelobacter venetianus sp. nov. Its physiology and ecological significance, as well as the importance and possible mechanism of anaerobic polyether degradation, are discussed.
\end{abstract}

Polyethylene glycol (PEG) is a synthetic water-soluble polymer of the common structural formula $\mathrm{H}\left(\mathrm{OCH}_{2} \mathrm{CH}_{2}\right)_{n} \mathrm{OH}$. PEGs of various molecular weights from 106 to 20,000 find broad application in the manufacturing of pharmaceuticals, cosmetics, lubricants, antifreeze agents, and even, in some countries, beer brewing. Moreover, most commercially produced nonionic detergents contain PEGs as hydrophilic moieties (6). Although vast amounts of this material are produced by the chemical industry, information on its biodegradability is scarce and contradictory. Whereas short-chain PEGs with molecular weights up to 600 are aerobically degraded $(16,33)$, PEGs with molecular weights higher than 1,000 are considered "bioresistant" (12). Other authors $(20,24,26,27,32)$ have reported complete degradation of PEGs with molecular weights up to 20,000 by pure and mixed cultures of aerobic bacteria. The only effort to effect anaerobic degradation of PEGs reported so far (30) has been of limited success: production of methane was low, and biological oxygen demand of the substrate decreased by only $32 \%$.
The present study was carried out to test whether aliphatic polyethers can be degraded in the absence of molecular oxygen. Ether bonds usually are biotically cleaved by peroxides or peroxide radicals, and this is probably one of the reasons for the lack of degradation of lignin under anaerobic conditions (45). However, at least methylarylethers can be split in the absence of oxygen by Acetobacterium woodii in a so-far-unknown, possibly hydrolytic reaction (3). The present paper shows that the depolymerization of PEG was catalyzed by anaerobic bacteria and occurred probably via hydrolysis after a modification of the terminal ethylene glycol (EG) unit.

\section{MATERIALS AND METHODS}

Strains. The following strains were isolated in pure culture from mud sample enrichments: Gra PEG 1, Gra PEG 2, and Gra EG 12 (anaerobic mud of Canale Grande, a channel in Venice, Italy); and Ko PEG 2 (anaerobic mud of a municipal sewage sludge digestor at Konstanz, West Germany). Methanospirillum hungatei M $1 \mathrm{~h}$ was isolated from digested sludge of the sewage plant at Göttingen, West Germany, and culti- 


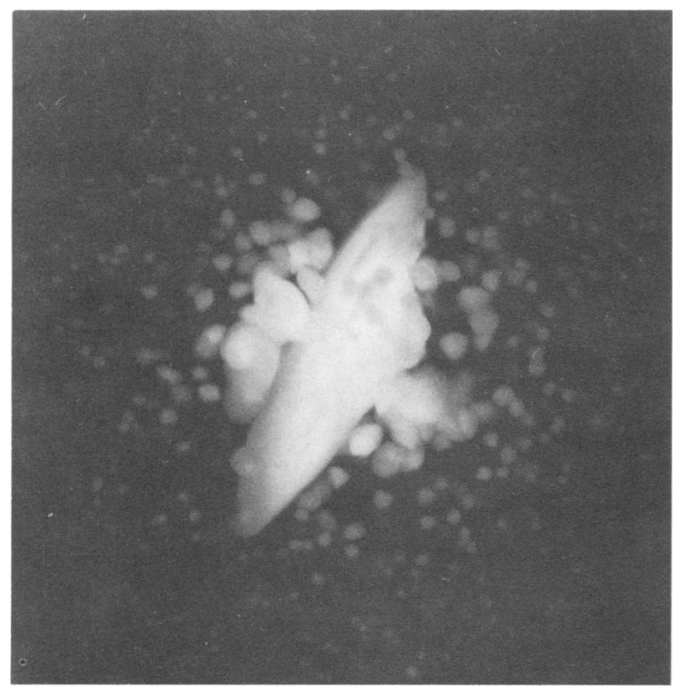

FIG. 1. Central and surrounding colonies of strains Gra PEG 1 and Gra EG 12 in an agar shake dilution tube with PEG as the sole organic substrate. Diameter of central colony, about $1.5 \mathrm{~mm}$.

vated on freshwater and salt water media with $10 \mathrm{mM}$ acetate under $\mathrm{H}_{2}-\mathrm{CO}_{2}(4: 1)$. A. woodii $\mathrm{NZva16}$ and NZva24 (3) were provided by R. Bache, Universität Konstanz.

Media and growth conditions. Carbonate-buffered, sulfide-reduced mineral medium with a low phosphate content was prepared as previously described (43). Trace element solution SL7 (1 ml/liter) and a vitamin solution ( $5 \mathrm{ml} /$ liter) (35) were added to the complete autoclaved medium from stock solutions. The $\mathrm{pH}$ was adjusted after autoclaving to 7.2 to 7.4 . For enrichment cultures, $50-\mathrm{ml}$ portions of medium were dispensed into $120-\mathrm{ml}$ serum bottles gassed with $\mathrm{N}_{2}-\mathrm{CO}_{2}$ (4:1); the bottles were then sealed with butyl rubber stoppers. For pure cultures, medium was dispensed into rubber-sealed $50-\mathrm{ml}$ screw cap bottles or $20-\mathrm{ml}$ screw cap tubes, both of which were completely filled. Substrate solutions were either autoclaved or filter sterilized as $\mathrm{NaOH}$-neutralized concentrates and added before inoculation.

Growth was followed in 20-ml tubes (15.6-mm diameter) in a Spectronic 70 spectrophotometer (Bausch \& Lomb, Inc., Rochester, N.Y.). Some tests for characterization were carried out with commercial medium systems (BioMerieux, Nürtingen, West Germany). All growth tests were carried out at least in duplicate at $28^{\circ} \mathrm{C}$ unless otherwise indicated.

Isolation. Pure cultures were obtained by repeated application of the agar shake culture method described by Pfennig (35). Tubes were gassed with $\mathrm{N}_{2}-\mathrm{CO}_{2}$ (4:1) and sealed with butyl rubber stoppers. Purity was checked microscopically and also by growth tests in complex AC medium (Difco Laboratories, Detroit, Mich.) with or without $0.1 \%$ PEG. Gram staining was carried out as previously described (28) without counterstaining. An unidentified Bacillus strain and Escherichia coli were used as controls.

Chemical analyses. Sulfide formation from sulfur or sulfate was analyzed by the methylene blue method
(11). Formation of nitrite from nitrate was assayed by determining azo dye formation with sulfanilic acid and $\alpha$-naphthylamine. Alcohols, volatile fatty acids, and methane were assayed by the gas chromatographic method previously described (36). PEG was quantified with phosphomolybdic acid by the method of Stevenson (37).

DNA base composition. Moles percent guanine-pluscytosine contents of the DNAs were determined by the thermal denaturation method previously described (13) after DNA extraction (29).

Cytochromes. Cytochromes were assayed in French press extracts of PEG-grown cells. Crude extracts, as well as membrane fractions prepared by $120 \mathrm{~min}$ of centrifugation at $100,000 \times g$ (Ivan Sorvall, Inc., Norwalk, Conn.), were subjected to difference spectroscopy in a model 250 spectrophotometer (Gilford Instrument Laboratories, Inc., Oberlin, Ohio).

Chemicals. All chemicals were of reagent grade and were obtained from E. Merck AG, Darmstadt, West Germany; Serva, Heidelberg, West Germany; and Fluka AG Neu-Ulm, West Germany. PEG preparations were purchased from Merck-Schuchardt (diethylene glycol [Di-EG] and PEG 200), Serva (PEGs 6,000 and 20,000), and EGA Chemie, Steinheim, West Germany (triethylene glycol [Tri-EG]).

\section{RESULTS}

Enrichment and isolation. We inoculated 50-ml enrichments in freshwater and salt water media plus $0.1 \%$ PEG 20,000 with 3 - to 5 -ml portions of anaerobic mud from creeks, sewage plants, and marine sediments. Gas production started after 8 to 12 days and ceased after 4 to 5 weeks. In subcultures on the same media, turbidity developed within 4 to 7 days, with little gas production. In further subcultures, mainly short straight rods were visible, with $M$. hungatei-like cells in young cultures and Methanothrix soehngenii-like cells in aged cultures. Isolation of the primary PEG-degrading organism was attempted in agar shake series. Developing colonies were of at least two morphological types: large central white colonies and surrounding smaller white colonies, which were more numerous than the central ones. The satellites only grew closely to the central colonies (Fig. 1).

Selective isolation was finally achieved by repeated transfer of the central colonies with sterile Pasteur pipettes into agar shake dilution series with PEG 20,000 as the substrate. The surrounding colonies could be purified in agar shake dilution series with EG as the substrate.

Enumeration of PEG-degrading bacteria by the three-tube most-probable-number technique (2) revealed 2,400 cells per $\mathrm{ml}$ in Canale Grande mud and 240 cells per $\mathrm{ml}$ in anaerobic sewage sludge. Two pure cultures of PEG-utilizing bacteria were isolated from Canale Grande mud in salt water medium (strains Gra PEG 1, Gra PEG 2), and one was isolated from the digested sludge of a sewage plant in freshwater medium (strain 


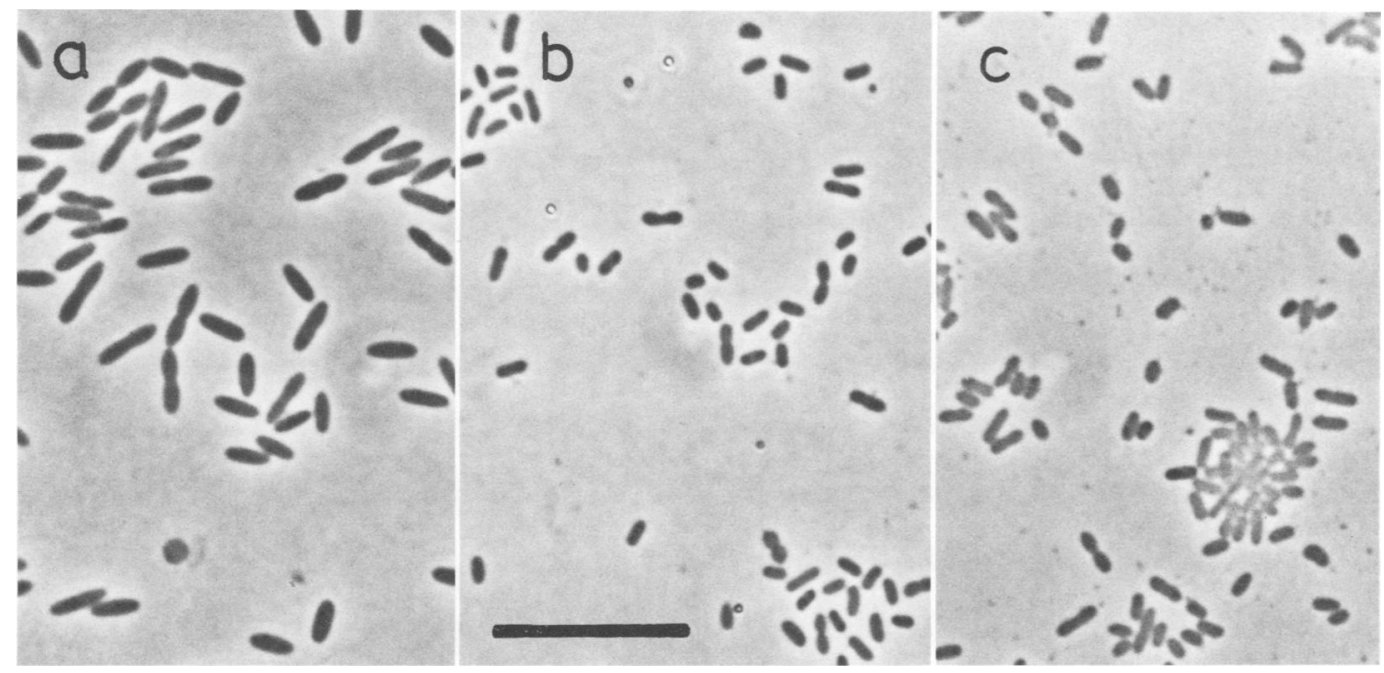

FIG. 2. Phase-contrast micrographs of isolates from PEG enrichments. (a) Strain Gra EG 12 grown on EG; (b) strain Gra PEG 1 grown on PEG; (c) strain Gra PEG 2 grown on PEG. Bar = $10 \mu \mathrm{m}$ (for all panels).

Ko PEG 2). One EG-degrading culture was isolated from Canale Grande mud in salt water medium (strain Gra EG 12). All of these strains were characterized further.

Characterization of strain Gra EG 12. Cells of strain Gra EG 12 were straight rods, 0.8 by 2 to 4 $\mu \mathrm{m}$ in size, and slightly pointed at the ends (Fig. 2a). Cells were motile and nonsporeforming and stained gram negative to weakly positive. Growth was found on EG, formate, methanol, $\mathrm{H}_{2}-\mathrm{CO}_{2}$, and trimethoxybenzoate. Acetate was the only fermentation product, except for gallic acid, which was produced on trimethoxybenzoate. It was evident from these results that strain Gra EG 12 belongs to the species $A$. woodii. Other strains of $A$. woodii (NZva16 and Nzva24) could also be grown on EG. PEG was not degraded.

Characterization of PEG-fermenting strains. (i) Morphology and cytological characteristics. Cells of all isolates were short straight rods, 0.5 by 1.0 to $2.5 \mu \mathrm{m}$ in size, and rounded at the ends (Fig. $2 b$ and $c)$. Strain Gra PEG 2 tended to form clumps (Fig. 2c) and grow on the walls of the glass culture tubes. All strains moved, at least in young cultures, in a tumbling manner suggesting polar to subpolar flagellation. All strains stained gram negative. Ultrathin sections showed multilayered cell walls typical of gram-negative bacteria (Fig. 3).

None of our isolates formed spores on mineral medium or special sporulation media $(15,23)$ with additional salt and $0.1 \%$ PEG as the substrate. PEG-degrading organisms could not be enriched with pasteurized mud.

The DNA guanine-plus-cytosine content of strains Gra PEG 1, Gra PEG 2, and Ko PEG 2, as determined separately by thermal denaturation, was $52.2 \pm 1.0 \mathrm{~mol} \%$. By redox difference spectroscopy, cytochromes could not be detected in Gra PEG 1 crude extracts or isolated membrane and cytoplasm fractions.

(ii) Physiological and nutritional properties. All PEG-fermenting strains grew only on oligo- and polymeric PEG, not on the monomer. Furthermore, they degraded some PEG-containing detergents, ethoxy ethanol, 1,2-propanediol, 1,2butanediol, glycerol, and acetoin. All substrates tested for ability to support growth are listed in Table 1. For growth on propandiol, butanediol, and glycerol, acetate had to be present as a source of carbon. Yeast extract was not utilized and did not enhance growth rates or yields on

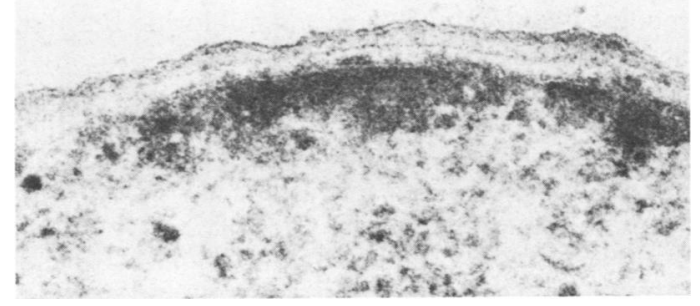

FIG. 3. Electron micrograph of an ultrathin section of strain Gra PEG 1 after fixation and staining with $3 \%$ glutaraldehyde and $1 \%$ osmium tetroxide. Bar $=0.1$ $\mu \mathrm{m}$. 
TABLE 1. Substrates utilized by PEG-fermenting isolates

\begin{tabular}{llccc}
\hline \multirow{2}{*}{\begin{tabular}{l} 
Substrate \\
\cline { 3 - 5 }
\end{tabular}} & $\begin{array}{c}\text { Amt per } \\
\text { liter }\end{array}$ & $\begin{array}{c}\text { Gra } \\
\text { PEG 1 }\end{array}$ & $\begin{array}{c}\text { Gra } \\
\text { PEG 2 }\end{array}$ & $\begin{array}{c}\text { Ko } \\
\text { PEG 2 }\end{array}$ \\
\hline EG & $20 \mathrm{mmol}$ & - & - & - \\
Di-EG & $10 \mathrm{mmol}$ & + & + & + \\
Tri-EG & $6.7 \mathrm{mmol}$ & + & + & + \\
PEG 200 & $1.0 \mathrm{~g}$ & + & + & + \\
PEG 6,000 & $1.0 \mathrm{~g}$ & + & + & + \\
PEG 20,000 & $1.0 \mathrm{~g}$ & + & + & + \\
Brij 58 & $1.0 \mathrm{~g}$ & + & ND & - \\
Triton X-100 & $1.0 \mathrm{~g}$ & - & ND & - \\
Triton X-114 & $1.0 \mathrm{~g}$ & + & ND & - \\
Tween 80 & $2.0 \mathrm{~g}$ & + & ND & - \\
Ethoxyethanol & $10 \mathrm{mmol}$ & + & + & + \\
1,2-Propanediol & $10 \mathrm{mmol}$ & $+^{c}$ & ND & + \\
1,2-Butanediol & $10 \mathrm{mmol}$ & $+^{c}$ & ND & ND \\
Glycerol & $10 \mathrm{mmol}$ & $+^{c}$ & ND & ND \\
Ethanol & $10 \mathrm{mmol}$ & $+^{d}$ & $+^{d}$ & $+^{d}$ \\
\hline
\end{tabular}

${ }^{a}$ No growth was found on any of the following substrates: glycolaldehyde, glyoxal, glyoxylate, glycolate, oxalate, polypropylene glycol, diethyl ether, dimethoxyethane, methoxyacetate, 1,3-propanediol, 1,3-butanediol, 1,4-butanediol, 2,3-butanediol, and 2,3-butanedione; methanol, propanol, isopropanol, and mannitol; malonate, succinate, fumarate, malate, L-tartrate, oxaloacetate, and citrate; glucose, fructose, mannose, xylose, and arabinose; formate, acetate, lactate, pyruvate, glycerate, and $\mathrm{H}_{2}-\mathrm{CO}_{2}$; glycine, methionine, serine, and threonine; and yeast extract, Casamino Acids, and peptone. Substrace concentrations were as follows: sugars, $2 \mathrm{mmol} \cdot \operatorname{liter}^{-1}$; yeast extract, Casamino Acids, peptone, and polypropylene glycol, $0.1 \%$; all others, $10 \mathrm{mmol} \cdot$ liter $^{-1}$.

${ }^{b}$ ND, Not determined.

${ }^{c}$ Growth was only possible in the presence of $5 \mathrm{mM}$ acetate.

${ }^{d}$ Growth was only possible in coculture with $M$. hungatei or $A$. woodii.

other substrates. None of the isolates reduced sulfate, sulfur, thiosulfate, or nitrate.

All strains grew well in their isolation media. Vitamins and the trace elements molybdenum, selenium, and tungsten, although present in the isolation media, were not required for growth. Freshwater isolate Ko PEG 2 also grew in medium containing $1 \%$ sodium chloride but not at higher salt concentrations, whereas the marine isolates could adapt to lower salt concentrations than present in their isolation medium; however, growth in freshwater medium was poor. Phosphate concentrations up to $50 \mathrm{mM}$ were tolerated by strain Gra PEG 1, but the other strains only tolerated up to $20 \mathrm{mM}$. During growth on PEG or acetoin, ethanol and acetate were the only fermentation products and were formed in nearly equimolar amounts. Since cell material was less reduced than PEG, ethanol formation usually exceeded acetate formation.

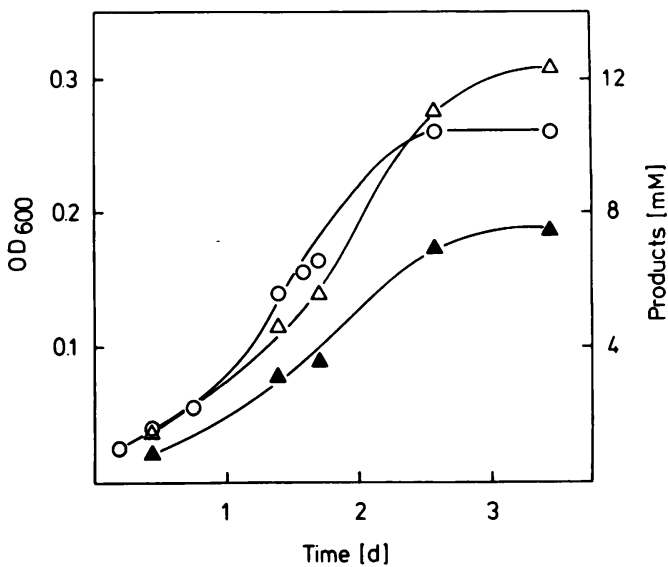

FIG. 4. Fermentation time course of strain Gra PEG 1 on mineral medium containing $0.1 \%$ PEG 20,000 . Experiments were performed at $30^{\circ} \mathrm{C}$ in $20-\mathrm{ml}$ sealed tubes. Samples for product analysis were removed with a syringe, and the headspaces were flushed with $\mathrm{N}_{2}-\mathrm{CO}_{2}$. Symbols: $\bigcirc$, cell density; $\boldsymbol{\Delta}$, acetate; $\triangle$, ethanol formed. $\mathrm{OD}_{600}$, Optical density at $600 \mathrm{~nm}$

When grown on 1,2-propanediol or 1,2-butanediol, propanol and propionate or butanol and butyrate, respectively, were the sole fermentation products. On glycerol, 1,3-propanediol and an unidentified acid (possibly $\beta$-hydroxypropionic acid) were formed. The correlation between growth and product formation on PEG is shown in Fig. 4. The cell yields were, to some extent, linearly dependent on the amount of substrate (PEG) present; however, PEG concentrations higher than $0.5 \%$ inhibited growth (Fig. 5). Yields of strain Ko PEG 2 were much lower

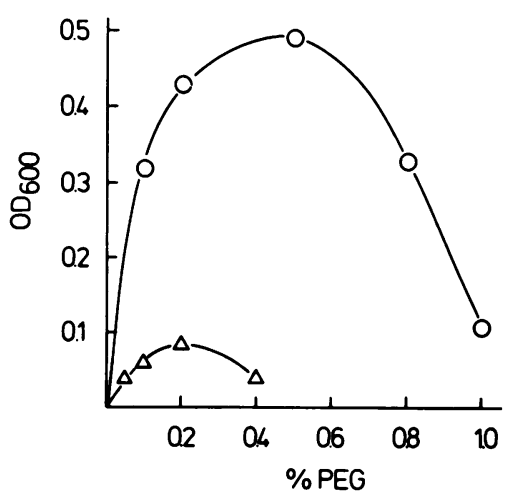

FIG. 5. Dependence of Gra PEG 1 and Ko PEG 1 growth on PEG concentration. Cell densities were recorded daily after inoculation, and maximum values reached after 1 week of incubation are given. Symbols: $O$, Gra PEG 1 in salt water medium; $\triangle$, Ko PEG 1 in freshwater medium. $\mathrm{OD}_{600}$, Optical density at $600 \mathrm{~nm}$. 
TABLE 2. Growth yields and stoichiometry of fermentation by strain Gra PEG $1^{a}$

\begin{tabular}{lccccccccc}
\hline \multicolumn{1}{c}{ Substrate } & $\begin{array}{c}\text { Amt per } \\
\text { liter }\end{array}$ & $\begin{array}{c}\text { OD }_{650} \\
\text { reached }^{b}\end{array}$ & $\begin{array}{c}\text { Substrate } \\
\text { degraded } \\
(\mu \mathrm{mol})\end{array}$ & $\begin{array}{c}\text { Cell dry wt } \\
\text { formed } \\
(\mathrm{mg})^{c}\end{array}$ & $\begin{array}{c}\text { Substrate } \\
\text { assimilated } \\
(\mu \mathrm{mol})^{d}\end{array}$ & $\begin{array}{c}\text { Product formed } \\
(\mu \mathrm{mol})\end{array}$ & $\begin{array}{c}\text { Growth } \\
\text { yield }\end{array}$ & $\begin{array}{c}\text { C recovery } \\
(\%)\end{array}$ \\
\hline PEG 20,000 & $1.0 \mathrm{~g}$ & 0.31 & $455^{e}$ & 1.37 & 47.2 & 218 & 206 & 3.02 & 101.6 \\
PEG 6,000 & $1.0 \mathrm{~g}$ & 0.13 & $455^{e}$ & 0.57 & 20.0 & 228 & 190 & 1.25 & 94.1 \\
PEG 200 & $1.0 \mathrm{~g}$ & $\mathbf{0 . 1 8}$ & $412^{e}$ & 0.80 & 27.0 & 208 & 200 & 1.94 & 103.2 \\
Tri-EG & $10 \mathrm{mmol}$ & $\mathbf{0 . 4 1}$ & $\mathbf{6 0 0}$ & 1.81 & 63.1 & 340 & 230 & 3.02 & 103.8 \\
Di-EG & $10 \mathrm{mmol}$ & 0.30 & $400^{e}$ & 1.33 & 46.2 & 224 & 170 & 3.33 & 107.5 \\
Ethoxyethanol & $10 \mathrm{mmol}$ & 0.13 & 200 & 0.57 & 20.0 & 288 & 112 & 2.85 & 102.5 \\
Acetoin & $10 \mathrm{mmol}$ & 0.31 & 200 & 1.37 & 47.2 & 221 & 172 & 6.85 & 107.6 \\
\hline
\end{tabular}

a All values are means of at least two independent assays.

${ }^{b} \mathrm{OD}_{650}$, Optical density at $650 \mathrm{~nm}$.

c Calculated by determining cell density from calibrated $500-\mathrm{ml}$ cultures.

${ }^{d}$ Calculated as EG monomers assimilated by the equation:

$$
7 \mathrm{C}_{2} \mathrm{H}_{6} \mathrm{O}_{2} \rightarrow 2 \mathrm{C}_{4} \mathrm{H}_{7} \mathrm{O}_{3}+3 \mathrm{C}_{2} \mathrm{H}_{6} \mathrm{O}+5 \mathrm{H}_{2} \mathrm{O}
$$

thus, $33.98 \mu \mathrm{mol}$ of EG was degraded to form $1 \mathrm{mg}$ of dry cell material plus $14.56 \mu \mathrm{mol}$ of ethanol.

e Calculated as EG monomers degraded.

than those of strain Gra PEG 1, and the inhibitory effect of higher PEG concentrations was even more pronounced.

The maximum growth rate of strain Gra PEG 1 on PEG was $0.0866 \mathrm{~h}^{-1}$ (minimum doubling time, $8.0 \mathrm{~h}$ ) at $33^{\circ} \mathrm{C}$. No growth occurred at temperatures lower than $10^{\circ} \mathrm{C}$ and higher than $40^{\circ} \mathrm{C}$. The optimum $\mathrm{pH}$ was 7.0 to 7.5 ; the $\mathrm{pH}$ limits were 5.5 and 8.0.

(iii) Growth yields and stoichiometry. The formation of fermentation products by strain Gra PEG 1 and the corresponding yields of dry cell matter are summarized in Table 2. The growth yield with PEG 20,000 as the substrate was 3.02 $\mathrm{g}$ (dry weight) per mol of EG monomer and was about the same on all oligo- and polymers used. All PEG compounds were completely degraded, as indicated by the stoichiometry of product formation. Less than $2 \%$ of the PEG used was detected in the spent medium. On acetoin, the molar growth yield was about twice as high as that on PEG (calculated as EG monomers). Similar results were obtained for strains Gra PEG 2 and Ko PEG 2; however, growth yields of the latter (freshwater) strain were lower (1.2 to $1.8 \mathrm{~g}$ (dry weight) per mol of monomeric PEG). The fermentation equation for PEG degradation can be written as follows:

$$
\begin{aligned}
& \mathrm{H}\left(\mathrm{OCH}_{2} \mathrm{CH}_{2}\right)_{n} \mathrm{OH}+\left(\frac{n}{2}-1\right) \mathrm{H}_{2} \mathrm{O} \rightarrow \\
& \frac{n}{2} \mathrm{CH}_{3} \mathrm{COO}^{-}+\frac{n}{2} \mathrm{H}^{+}+\frac{n}{2} \mathrm{CH}_{3} \mathrm{CH}_{2} \mathrm{OH}
\end{aligned}
$$

That for acetoin degradation is:

$$
\begin{gathered}
\mathrm{H}_{3} \mathrm{C}-\mathrm{CHOH}-\mathrm{CO}-\mathrm{CH}_{3}+\mathrm{H}_{2} \mathrm{O} \rightarrow \mathrm{CH}_{3} \mathrm{COO}^{-} \\
+\mathrm{H}^{+}+\mathrm{CH}_{3} \mathrm{CH}_{2} \mathrm{OH}
\end{gathered}
$$

That for butanediol, propanediol, and glycerol degradation is:

$$
\begin{gathered}
2 \mathrm{R}-\mathrm{CHOH}-\mathrm{CH}_{2} \mathrm{OH} \rightarrow \mathrm{R}-\mathrm{CH}_{2}-\mathrm{COO}^{-}+ \\
\mathrm{H}^{+}+\mathrm{R}-\mathrm{CH}_{2}-\mathrm{CH}_{2} \mathrm{OH}+\mathrm{H}_{2} \mathrm{O}
\end{gathered}
$$

Mechanism of PEG degradation. Since the polymer-degrading strains did not utilize monomeric EG, its influence on degradation of the polymer was studied. At $1 \mathrm{mmol} \cdot$ liter $^{-1}$, EG completely inhibited PEG degradation. Furthermore, filter-sterilized spent medium of growing or outgrown cells of strain Gra PEG 1 did not allow growth of the EG-fermenting strain Gra EG 12 on PEG. We conclude that strain Gra PEG 1 does not excrete extracellular hydrolytic enzymes for PEG hydrolysis and that EG is not formed extracellularly during PEG degradation.

Coculture experiments. In coculture with $M$. hungatei or $A$. woodii, strain Gra PEG 1 fermented PEG completely to acetate and, probably, hydrogen, which was used by the hydrogenconsuming strains for formation of methane or acetate (Table 3). The fermentation equations for the respective cocultures were as follows:

$$
\begin{gathered}
\mathrm{HO}\left(\mathrm{CH}_{2}-\mathrm{CH}_{2}-\mathrm{O}\right)_{4} \mathrm{H}+\mathrm{HCO}_{3}^{-} \rightarrow \\
4 \mathrm{H}_{3} \mathrm{COO}^{-}+3 \mathrm{H}^{+}+\mathrm{CH}_{4} \\
\mathrm{HO}\left(\mathrm{CH}_{2}-\mathrm{CH}_{2}-\mathrm{O}\right)_{4} \mathrm{H}+2 \mathrm{HCO}_{3}^{-} \\
5 \mathrm{CH}_{3} \mathrm{COO}^{-}+3 \mathrm{H}^{+}+\mathrm{H}_{2} \mathrm{O}
\end{gathered} \rightarrow
$$

Since EG was not formed extracellularly from PEG by strain Gra PEG 1, we had to assume that the trophic relationship between strains Gra PEG 1 and Gra EG 12 (Fig. 1) depended on interspecies hydrogen transfer (second equation). The cell yields were significantly increased in cocultures, compared with pure culture results (Table 3). 
TABLE 3. Growth yields and stoichiometry of fermentation by strain Gra PEG 1 in coculture with A. woodii or $M$. hungatei ${ }^{a}$

\begin{tabular}{|c|c|c|c|c|c|c|}
\hline \multirow{2}{*}{ Substrate } & \multirow{2}{*}{$\begin{array}{c}\text { Substrate } \\
\text { degraded } \\
(\mu \mathrm{mol})\end{array}$} & \multirow{2}{*}{ Coculture with: } & \multicolumn{2}{|c|}{ Product formed $(\mu \mathrm{mol})^{b}$} & \multirow{2}{*}{$\begin{array}{l}\text { Growth yield } \\
\left(\mathrm{g} \cdot \mathrm{mol}^{-1}\right)^{c}\end{array}$} & \multirow{2}{*}{$\begin{array}{c}\mathrm{C} \text { recovery } \\
(\%)^{c}\end{array}$} \\
\hline & & & Acetate & Methane & & \\
\hline PEG 20,000 & $\begin{array}{l}113.5^{d} \\
227^{d}\end{array}$ & $\begin{array}{l}\text { M. hungatei } \\
\text { A. woodii }\end{array}$ & $\begin{array}{l}110 \\
235\end{array}$ & 26 & $\begin{array}{l}4.48 \\
4.1\end{array}$ & $\begin{array}{r}109 \\
94\end{array}$ \\
\hline Ethanol & $\begin{array}{l}100 \\
200\end{array}$ & $\begin{array}{l}\text { M. hungatei } \\
\text { A. woodii }\end{array}$ & $\begin{array}{r}87 \\
234\end{array}$ & 46 & $\begin{array}{l}2.88 \\
2.43\end{array}$ & $\begin{array}{l}98 \\
84.3\end{array}$ \\
\hline EG & 200 & A. woodii alone & 267 & & 5.75 & 102 \\
\hline
\end{tabular}

${ }^{a}$ Experiments were carried out in salt water medium with preadapted strains grown on PEG or $\mathrm{H}_{2}-\mathrm{CO}_{2}$.

${ }^{b}$ In each coculture and in a culture of $A$. woodii alone, $<0.1 \mu \mathrm{mol}$ of ethanol was formed.

$c$ Calculated via cell density for the entire cell suspension as described in Table 2.

${ }^{d}$ Calculated as EG monomers degraded.

Cocultures of strain Gra PEG 1 and $M$. hungatei or $A$. woodii could also be grown on ethanol as the sole source of carbon and energy. The results (Table 3 ) agree with the following equations:

$$
\begin{gathered}
2 \mathrm{CH}_{3} \mathrm{CH}_{2} \mathrm{OH}+ \\
+\mathrm{HCO}_{3}^{-} \rightarrow 2 \mathrm{CH}_{3} \mathrm{COO}^{-}+\mathrm{H}^{+} \\
+\mathrm{CH}_{4}+\mathrm{H}_{2} \mathrm{O} \\
2 \mathrm{CH}_{3} \mathrm{CH}_{2} \mathrm{OH}+2 \mathrm{HCO}_{3}^{-} \rightarrow 3 \mathrm{CH}_{3} \mathrm{COO}^{-}+\mathrm{H}^{+} \\
+2 \mathrm{H}_{2} \mathrm{O}
\end{gathered}
$$

\section{DISCUSSION}

Aerobic microorganisms split ether bonds by means of oxygenases, peroxides, or peroxide radicals, as occurs during demethoxylation of lignin phenyl moieties or depolymerization of lignin $(5,13,16,21)$. Since all of these reactions require molecular oxygen as an active reactant, the splitting of ether bonds has been thought to be possible only in the presence of oxygen; this has been accepted as a reason for the lack of degradation of lignin under anaerobic conditions. Recently, however, anaerobic demethoxylation of several methoxylated aromatic acids has been shown (3): $A$. woodii apparently cleaves the aryl-methyl ether bridge hydrolytically and ferments the methoxyl groups to acetate. Since phenols are much more acidic than aliphatic alcohols, a phenyl ether might behave more like an acylester than an aliphatic ether.

Aerobic degradation of PEG has been studied by several groups (reviewed in reference 12). In most of the systems studied, the initial attack on the polymer is oxidation of the terminal EG monomer to the corresponding glycolaldehyde derivative by intracellular NAD-, flavine adenine dinucleotide-, or ferricyanide-dependent dehydrogenase reactions $(25,27,34)$. Other authors have found dichlorophenol-, indophenoldependent dehydrogenation to the corresponding enol derivative, which is later hydrated to the glycolaldehyde half-acetal derivative (41). Haines and Alexander (20) have reported an extracellular enzyme which depolymerizes longchain PEGs, probably by a hydrolytic reaction. Their strain, however, was lost, and their results could not be achieved by other authors (12). In general, it appears probable that during aerobic PEG degradation, the first attack on the polymer is dehydrogenation.

The monomers obtained are probably further metabolized via the glyoxylate or glycerate pathway, as has been shown for the degradation of EG by aerobic bacteria $(9,10)$. In a Mycobacterium culture, however, degradation of EG proceeds via initial dehydration and subsequent enol-ketone tautomerization to acetaldehyde, which is oxidized to acetate and metabolized further (44). Dehydration is also the typical initial reaction during anaerobic degradation of EG by Aerobacter aerogenes (1), Clostridium glycolicum $(18,42)$, and Klebsiella sp. $(18,42)$. The initial reaction has been characterized as coenzyme $B_{12}$ dependent (1), as have the analogous reactions with higher 1,2-diols (4). Thus, all anaerobic fermentations of EG lead to acetaldehyde as an intermediate, which is further disproportionated to acetate and ethanol.

Our experiments with anaerobic isolates on PEG indicate that there was no extracellular depolymerization to EG monomers. Rather, the polymer seemed to have been taken up into the cells and subsequently degraded inside. 1,2Propanediol, glycerol, 1,2-butanediol, and DiEG were the shortest polyols assimilated. The EG monomer could not be taken up; it blocked the uptake mechanism. The degradation of PEG inside the cells can proceed by two basically different pathways (Fig. 6). Either the polymer is hydrolyzed or the EG monomer is fermented to acetate and ethanol in the same way as is accomplished by other anaerobes. This hypothesis does not explain how ether splitting occurs 


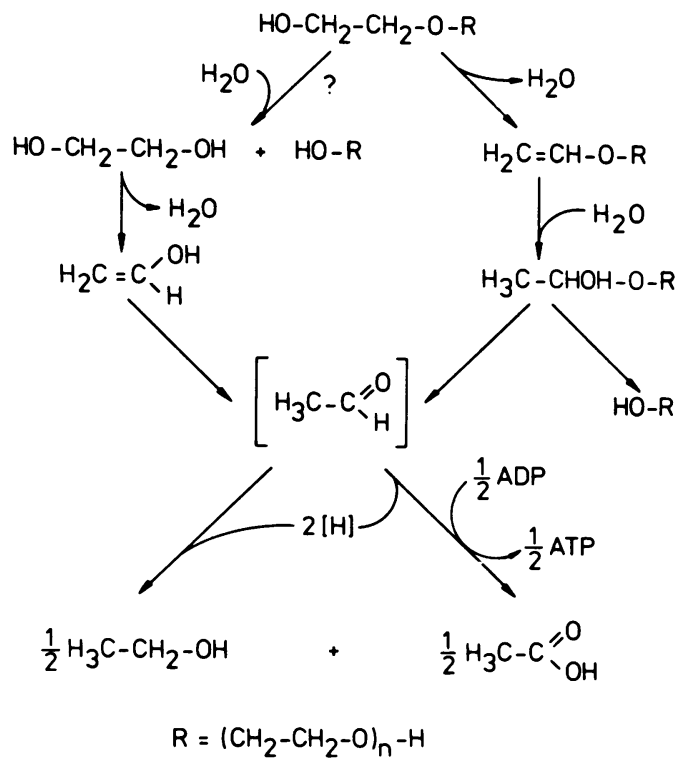

FIG. 6. Hypothetical pathways of PEG degradation by strain Gra PEG 1 . The compound in brackets (acetaldehyde) may be bound to a carrier.

under anaerobic conditions. An explanation of the mechanism would be possible by assuming that dehydration and rehydration of the terminal EG residue or a coenzyme $B_{12}$-dependent shift of the terminal hydroxy function to the corresponding acetaldehyde derivative occurs while the terminal is still bound to the polymer. The subsequent release of the acetaldehyde residue, either free or carrier bound, would then only involve hydrolytic cleavage of a half-acetal linkage, a reaction that can easily be catalyzed in the absence of oxygen.

The ultimate EG monomer remaining on a PEG chain was completely fermented, probably by the same mechanism, as the complete carbon recovery from degradation of oligomers indicates. Regardless of which of the two suggested PEG degradation pathways (Fig. 6) is used, EG has to be degraded in the cells. The inhibitory effect of EG on PEG utilization therefore probably affects the uptake system. This model, however, leaves us wondering how a synthetic molecule with a molecular weight of 20,000 can pass through the cytoplasmic membrane. The apparent resistance of our isolates to nonionic detergents is another point of interest for further studies.

Our results indicate that aliphatic ether bonds can be cleaved in the absence of molecular oxygen if there is another alcoholic function adjacent to either of the alcohols. This would, for example, be true for glycerol alkyl ether linkages in the membrane lipids of methane bacteria (39) but not for most of the ether linkages in lignin.

On the basis of the degradation pathway outlined above, the main energy-conserving reaction of our isolate appears to be the disproportionation of acetaldehyde to the corresponding acid and alcohol. Thus, $0.5 \mathrm{~mol}$ of ATP per mol of EG monomer metabolized can be conserved via the acetate kinase reaction. The growth yield obtained $\left(3.02 \mathrm{~g}\right.$ of cells [dry weight] $\left.\cdot \mathrm{mol}^{-1}\right)$ is in good agreement with this assumption; the calculated $Y_{\text {ATP }}$ from this yield would be 6.04 $\mathrm{g} \cdot \mathrm{mol}^{-1}$. At least there is no indication that further energy-conserving reactions are involved (38). Thus, the organism only conserves the free energy of the disproportionation reaction $\left(-37.02 \mathrm{~kJ} \cdot\right.$ mol of aldehyde $\left.{ }^{-1}\right)$, not that of the dehydration of EG to acetaldehyde $(-46.58$ $\mathrm{kJ} \cdot \mathrm{mol}^{-1}$; calculated after values given in reference 40), and the dehydrated PEG monomer would be bioenergetically equivalent to the hydrated EG. This assumption is supported by the fact that the cell yield of a coculture of strain Gra PEG 1 and $A$. woodii on PEG was equivalent to that of $A$. woodii alone on EG (Table 3 ). The yield on acetoin as an acetaldehyde dimer was about twice as high as that on the PEG monomer, which is again in good agreement with the above assumption. Yields on PEG were enhanced when a hydrogen-consuming bacterium like $A$. woodii or $M$. hungatei allowed complete oxidation of the $C_{2}$ units to acetate. The natural substrate our isolate used when no PEG was present in sediments remains to be identified. Since acetoin, 1,2-propanediol, and 1,2-butanediol are not important substrates or intermediates in anaerobic degradation, we suppose that the main metabolic role of our isolates in nature is either the fermentation of glycerol or the syntrophic oxidation of ethanol to acetate in a manner similar to that of the "Methanobacillus omelianskii"' S organism (7).

The observation that PEG and PEG-containing nonionic detergents can be at least partially degraded in anoxic ecosystems is of major environmental importance. Recent studies on aerobic degradation have revealed that only the PEG moiety of so-called biodegradable detergents is degraded, whereas the hydrophobic moiety is refractory and represents a violent hazard to several kinds of lower aquatic animals and fish (19; E. Stephanov and W. Giger, Environ. Sci. Technol., in press). Thus, detergents buried in anaerobic sediments of lakes and rivers may still contribute toxic compounds to aquatic environments.

Anaerobic degradation of PEG may have some advantages over aerobic degradation in industrial applications. We never observed that our isolates preferred long-chain polymers over 
short-chain substrates. In addition, many of the problems in aerobic PEG degradation may be caused by the chemical formation of toxic autoxidation products from PEGs by oxygen (21); these products are not formed under anoxic conditions.

Of economic interest is the partial degradation of nonionic detergents in the oil industry. Detergents of this type are also used as surfactants in secondary oil recovery technology (31) and may well prove to be suitable substrates for sulfatereducing bacteria involved in corrosion processes. PEG-degrading, sulfate-reducing bacteria were also isolated in our laboratory.

The PEG-degrading isolates, irrespective of their origin and salt requirements, were similar to one another with respect to substrate utilization, physiology, and cytological characteristics. As obligately anaerobic, gram-negative, nonsporeforming rods, they should be assigned to the family Bacteroidaceae (8). Owing to their unique metabolism and their inability to utilize sugars, they cannot be assigned to any of the existing genera in this family. However, they share some basic properties with the gallic acidfermenting new species Pelobacter acidigallici (36), namely lack of sugar utilization, utilization of only a small range of substrates, production of acetate as the main fermentation product, and nearly the same DNA base ratio. We therefore propose that our isolates constitute a new species, Pelobacter venetianus sp. nov. (ve'ne'ti-a' nus L. n. venetianus from Venice, the origin of the type strain and the place where it occurs in high numbers). The cells are rod shaped, 0.5 by 1.0 to $2.5 \mu \mathrm{m}$ in size, and rounded at the ends. They occur singly or in pairs, are motile in young cultures, do not form spores, and stain gram negative.

$P$. venetianus is a strictly anaerobic chemoorganotroph. PEG, PEG-containing compounds, and acetoin were the only substrates it utilized. The substrates were fermented to nearly equal amounts of acetate and ethanol. 1,2-Propanediol, 1,2-butanediol, and glycerol were also fermented to the corresponding acids and alcohols, but for growth, acetate was necessary as a source of carbon. Sulfate, sulfur, thiosulfate, and nitrate were not reduced. Growth required mineral media with a reductant. Growth yields and rates of the type strain were higher on media containing at least $10 \mathrm{~g}$ of $\mathrm{NaCl}$ and $1.5 \mathrm{~g}$ of $\mathrm{MgCl}_{2} \cdot 6 \mathrm{H}_{2} \mathrm{O}$ per liter. No growth factors or vitamins were required. Indole was not formed from tryptophan, and gelatin and urea were not hydrolyzed. In coculture with a hydrogen-consuming methanogenic or homoacetogenic bacterium, growth on ethanol was achieved by oxidation of ethanol to acetate. Selective enrichment with PEG as the sole substrate was accom- plished. The $\mathrm{pH}$ range was 5.5 to 8.0 (optimum, 7.0 to 7.5 ). The growth temperature range was 10 to $40^{\circ} \mathrm{C}$ (optimum, $33^{\circ} \mathrm{C}$ ). No cytochromes were detectable. The DNA base ratio was 52.2 $\pm 1.0 \mathrm{~mol} \%$ guanine plus cytosine (determined by thermal denaturation). Habitats include anaerobic mud of freshwater or marine origin. The type strain is Gra PEG 1 (= DSM 2394) and is deposited in Deutsche Sammlung von Mikroorganismen, Göttingen, West Germany.

\section{ACKNOWLEDGMENTS}

We thank Norbert Pfennig for support and valuable discussions and Waltraud Dilling for analysis of the DNA base composition and electron microscopic characterization of the cell wall structure in cooperation with Frank Mayer.

This work was supported by a grant from the Deutsche Forschungsgemeinschaft.

\section{LITERATURE CITED}

1. Abeles, R. H., and H. A. Lee, Jr. 1961. An intramolecular oxidation reduction requiring a cobamide coenzyme. $J$. Biol. Chem. 236:2347-2350.

2. American Public Health Association. 1965. Standard methods for the examination of water and wastewater including bottom sediments and sludge, p. 604-609. American Public Health Association, Inc., New York.

3. Bache, R., and N. Pfennig. 1981. Selective isolation of Acetobacterium woodii on methoxylated aromatic acids and determination of growth yields. Arch. Microbiol. 130:255-261.

4. Barker, H. A. 1972. Corrinoid-dependent enzymic reactions. Annu. Rev. Biochem. 41:55-90.

5. Bernhardt, F. H., H. Staudinger, and V. Ullrich. 1970. Eigenschaften einer p-Anisat-O-Demethylase im zellfreien Extrakt von Pseudomonas species. Hoppe-Seyler's Z. Physiol. Chem. 351:467-478.

6. Bock, K. J., and H. Stache. 1982. Surfactants, p. 163-199. In O. Hutzinger (ed.), The handbook of environmental chemistry, vol. 3B. Springer Verlag, Berlin.

7. Bryant, M. P., E. A. Wolin, M. J. Wolin, and R. S. Wolfe. 1967. Methanobacillus omelianskii, a symbiotic association of two species of bacteria. Arch. Microbiol. 59:20-31.

8. Buchanan, R. E., and N. E. Gibbons. 1974. Bergey's manual of determinative bacteriology, 8th ed. The Williams \& Wilkins Co., Baltimore.

9. Caskey, W. H., and W. A. Taber. 1981. Oxidation of ethylene glycol by a salt-requiring bacterium. Appl. Environ. Microbiol. 42:180-183.

10. Child, J., and A. Willetts. 1978. Microbial metabolism of aliphatic glycols. Bacterial metabolism of ethylene glycol. Biochim. Biophys. Acta 538:316-327.

11. Cline, J. D. 1969. Spectrophotometric determination of hydrogen sulfide in natural waters. Limnol. Oceanogr. 14:454-458.

12. Cox, D. P. 1978. The biodegradation of polyethylene glycols. Adv. Appl. Microbiol. 23:173-194.

13. DeLey, J. 1970. Reexamination of the association between melting point, buoyant density and the chemical base composition of deoxyribonucleic acid. J. Bacteriol. 101:738-754.

14. Donnelly, M. J., and S. Dagley. 1981. Bacterial degradation of 3,4,5-trimethoxycinnamic acid with production of methanol. J. Bacteriol. 147:471-476.

15. Duncan, C. L., and D. H. Strong. 1968. Improved medium for sporulation of Clostridium perfringens. Appl. Microbiol. 16:82-89.

16. Fincher, E. L., and W. J. Payne. 1962. Bacterial utilization of ether glycols. Appl. Microbiol. 10:542-547.

17. Forney, L. J., C. A. Reddy, and H. S. Pankratz. 1982. Ultrastructural localization of hydrogen peroxide produc- 
tion in ligninolytic Phanerochaete chrysosporium cells. Appl. Environ. Microbiol. 44:732-736.

18. Gaston, L. W., and E. R. Stadtman. 1963. Fermentation of ethylene glycol by Clostridium glycolicum sp. nov. J. Bacteriol. 85:356-362.

19. Giger, W. E., E. Stephanou, and C. Schaffner. 1981. Persistent organic chemicals on sewage effluents. I. Identifications of nonylphenols and nonylphenolethoxylates by glass capillary gas chromatography-mass spectrometry. Chemosphere 10:1254-1263.

20. Haines, J. R., and M. Alexander. 1975. Microbial degradation of polyethylene glycols. Appl. Microbiol. 29:621-625.

21. Hamburger, R., E. Azaz, and M. Donbrow. 1975. Autoxidation of polyethylenic non-ionic surfactants and of polyethylene glycols. Pharm. Acta Helv. 50:10-17.

22. Higuchi, T. 1982. Biodegradation of lignin: biochemistry and potential applications. Experientia 38:159-166.

23. Hollaus, F., and U. Sleytr. 1972. On the taxonomy and fine structure of some hyperthermophilic saccharolytic clostridia. Arch. Microbiol. 86:129-146.

24. Hosoya, H., N. Miyazaki, Y. Takanashi, M. Tsurufuji, M. Yamasaki, and G. Tamura. 1978. Bacterial degradation of synthetic polymers and oligomers with special reference to the case of polyethyleneglycol. Agric. Biol. Chem. 42:1545-1552.

25. Jones, N., and G. K. Watson. 1976. Ethylene glycol and polyethylene glycol catabolism by a sewage bacterium. Biochem. Soc. Trans. 4:891-892.

26. Kawai, F., M. Fukaya, Y. Tani, and K. Ogata. 1977. Identification of polyethylene glycols (PEGs)-assimilable bacteria and culture characteristics of PEG 6000 degradation by a mixed culture. J. Ferment. Technol. 55:429-435.

27. Kawai, F., M. Kimura, M. Fukaya, Y. Tani, K. Ogata, T. Ueno, and H. Fukami. 1978. Bacterial oxidation of polyethylene glycol. Appl. Environ. Microbiol. 35:679-684.

28. Magee, C. M., G. Rodeheaver, M. T. Edgerton, and R. F. Edlich. 1975. A more reliable Gram staining technique for diagnosis of surgical infections. Am. J. Surg. 130:341-346.

29. Marmur, J. 1961. A procedure for the isolation of deoxyribonucleic acid from microorganisms. J. Mol. Biol. 3:208218.

30. Mills, E. J., and V. T. Stack. 1954. Acclimation of microorganisms for the oxidation of pure organic chemicals, $p$. 449-464. Engineering bulletin, vol. 87. Purdue University Engineering Extension Service, Purdue University, Lafayette, Ind.

31. Moses, V., and D. G. Springham. 1981. Bacteria and the enhancement of oil recovery. Applied Science Publishers, London.

32. Ogata, K., F. Kawai, M. Fukaya, and Y. Tani. 1975. Isolation of polyethylene glycols-assimilable bacteria. J. Ferment. Technol. 53:757-761.

33. Patterson, S. J., C. C. Scott, and K. B. E. Tucker. 1970 Nonionic detergent degradation. III. Initial mechanism of the degradation. J. Am. Oil Chem. Soc. 47:37-41.

34. Payne, W. J., and R. L. Todd. 1966. Flavin-linked dehydrogenation of ether glycols by cell-free extracts of a soil bacterium. J. Bacteriol. 91:1533-1536.

35. Pfennig, N. 1978. Rhodocyclus purpureus gen. nov. and sp. nov., a ring-shaped, vitamin $\mathrm{B}_{12}$-requiring member of the family Rhodospirillaceae. Int. J. Syst. Bacteriol. 28:283-288.

36. Schink, B., and N. Pfennig. 1982. Fermentation of trihydroxybenzenes by Pelobacter acidigallici gen. nov. sp. nov., a new, strictly anaerobic, non-sporeforming bacterium. Arch. Microbiol. 133:195-201.

37. Stevenson, D. G. 1954. The absorptiometric determination of a nonionic detergent. Analyst (London) 79:504-507.

38. Stouthamer, A. H. 1979. The search for correlation between theoretical and experimental growth yields. Int. Rev. Biochem. 21:1-47.

39. Thauer, R. K., and G. Fuchs. 1979. Methanogene Bakterien. Naturwissenschaften 66:89-94.

40. Thauer, R. K., K. Jungermann, and K. Decker. 1977. Energy conservation in chemotrophic anaerobic bacteria. Bacteriol. Rev. 41:100-180.

41. Thélu, J., L. Medina, and J. Pelmont. 1980. Oxidation of polyethylene oligomers by an inducible enzyme from Pseudomonas P 400. FEMS Microbiol. Lett. 8:187-190.

42. Toraya, T., S. Honda, and S. Fukui. 1979. Fermentation of 1,2-propanediol and 1,2-ethanediol by some genera of Enterobacteriaceae, involving coenzyme $\mathrm{B}_{12}$-dependent diol dehydratase. J. Bacteriol. 139:39-47.

43. Widdel, F., and N. Pfennig. 1981. Studies on dissimilatory sulfate-reducing bacteria that decompose fatty acids. I. Isolation of new sulfate-reducing bacteria enriched with acetate from saline environments. Description of Desulfobacter postgatei gen. nov., sp. nov. Arch. Microbiol. 129:395-400.

44. Wiegant, W. M., and J. A. M. DeBont. 1980. A new route for EG metabolism in Mycobacterium E 44. J. Gen. Microbiol. 120:325-331.

45. Zeikus, J. G. 1981. Lignin metabolism and the carbon cycle: polymer biosynthesis, biodegradation and environmental recalcitrance. Adv. Microb. Ecol. 5:1-42. 